\title{
CONTROVERTIBILIDADE SEM CONTROVÉRSIA? ${ }^{1}$
}

\author{
Marcelo Dascal \\ Tradução de Bento Itamar Borges*
}

((1)) Wolfgang Sander propõe uma inovação significativa no pensamento pedagógico atual. Em termos conceituais, sua sugestão é renovar o conceito de "Bildung", do século XIX, por meio da inserção da controvertibilidade e da perspectividade como componentes essenciais do processo de ensino e aprendizagem, bem como do ideal de uma pessoa "instruída". ${ }^{2}$ Essa mudança conceitual, defende ele, requer uma alteração paralela nas noções de conhecimento e ciência, as quais ele propõe encarar do ponto de vista "construtivista". Na prática, a implementação dessa ideia demandaria com certeza uma extensa reforma do sistema educacional, inclusive uma abordagem radicalmente nova do magistério, dos currículos, da participação dos estudantes, do uso e do desenvolvimento de novas tecnologias na escola e até do cenário físico do ambiente da escolarização. O enfoque de Sander está principalmente centrado na fundamentação de sua proposta. Eu vou, naturalmente, acompanhá-lo nesse aspecto, considerando, sobretudo, embora não de modo exclusivo, o conceito de "controvertibilidade". Minhas considerações, todavia, implicam que seria um grave erro ignorar a dimensão prática desse conceito até mesmo para as análises teóricas que dele sejam feitas.

\footnotetext{
* Doutor em Filosofia pela Universidade Federal de Minas Gerais e Pós-doutor em Filosofia pela PUCRS. Professor do Instituto de Filosofia e do Programa de Pós Graduação em Filosofia (Mestrado) da Universidade Federal de Uberlândia (UFU). E-mail: bentoib@gmail.com

1 Tradução autorizada em 07/10/2010 do original: Controversiality without Controversy? Erwägen wissen Ethik 20 (2009). Heft 2. S. 254-257.

2 Devido à dificuldade de encontrar uma tradução adequada de "Bildung” ((29)) para o inglês, vou empregar esse termo mesmo no texto em inglês. [NT.: O termo, em português, pode ser igualmente traduzido por "educação" e por "formação", no sentido que remonta a Humboldt].
} 
((2)) Seja-me permitido dizer, de saída, que dou as boas-vindas à ênfase que Sander confere à controvertibilidade. Pois eu de fato creio que o mundo para o qual a escola tem que preparar de alguma forma os alunos para viver é - virtualmente em todos os seus aspectos - um mundo em que a controvertibilidade é a regra e não a exceção; isso significa que, no mínimo, não pode ser desconsiderado na esfera educacional. Em um mundo assim, a teoria e a prática educacionais não fazem sentido sem o reconhecimento da centralidade desse fato e sem levá-lo em conta. A questão que vou encaminhar é como tirar proveito da própria existência de controvérsias no contexto pedagógico. Isso me levará a examinar, do ponto de vista teórico, se é satisfatória a conceitualização que Sander fornece do universal fenômeno da controvérsia, tanto de maneira geral como para seus propósitos específicos. Esse exame, como veremos, revela que a controvérsia, qua atividade humana, é o tipo de fenômeno em que theoria e praxis estão entretecidas e são interdependentes (cf. DASCAL, 2006b) de maneira tão íntima que qualquer tentativa de tratar separadamente essas duas dimensões solapa tanto a compreensão do fenômeno quanto a possibilidade de sua efetiva aplicação à Bildung.

((3)) O ponto de partida de Sander é o chamado "Consenso de Beutelsbach", de 1976, resultado informal de um encontro sobre Bildung política disposto a resolver o debate que então se travava sobre a legitimidade do uso das escolas para a persuasão política ((1-2)). Três princípios, que se tornaram amplamente aceitos como a base para uma precisa demarcação entre Bildung política e doutrinação política nas escolas, na Alemanha e em outros lugares, formam o cerne do "Consenso" ((3)): 1. não é permitida a imposição de ideias, ou seja, não se pode impedir que os estudantes formem por si mesmos juízos independentes; 2. o que é controvertido em política e nas ciências deve ser como tal apresentado na sala de aula; 3 . o estudante deve ser colocado em uma posição na qual ele seja capaz de analisar a situação política e seus próprios interesses, bem como capaz de identificar meios para influenciar a situação em questão, de acordo com seus interesses. Segundo Sander, esses princípios - com exceção de certo debate sobre o terceiro - foram amplamente aceitos por delimitarem claramente o papel do professor em um sistema educacional democrático: 
as posições pessoais do professor e da professora são, como tais, colocadas de lado como um objeto de estudo ou discussão na sala de aula; eles não deveriam preponderar sobre outras ideias apesar da autoridade do professor ou talvez por causa dela; elas podem ser de interesse - e, por conseguinte, autorizadas a serem expressas ou discutidas em classe - apenas como uma das muitas posições de que se pode lançar mão na política ou na ciência $((5))$.

((4)) O objetivo de Sander é estender esses princípios além do âmbito da Bildung política, fornecendo-lhes fundamentação epistemológica. Após considerar esse passo, é válido um segundo olhar na direção dos princípios, pois parece existir uma certa inconsistência quanto a sua aplicação conjunta. Por exemplo, enquanto o princípio 1 trata de banir a influência do professor no julgamento dos estudantes ao proibir a expressão das posições daqueles nos assuntos que formam parte do programa de estudo, o princípio 3 aspira dar aos estudantes as ferramentas necessárias para analisar questões e interesses a fim de deliberarem sobre sua própria posição e seu curso de ação. De modo semelhante, embora o princípio 2 exija a apresentação do caráter controvertido das questões discutidas, o princípio 1 evita que o professor vá o tempo todo tomar parte de fato na resolução de controvérsias ao mostrar como ele ou ela pesaria os argumentos dos adversários e assim determinaria para qual dos lados a balança da razão pende (DASCAL, 2005). Com certeza, graças ao princípio 1, o "paradigma bancário" da transmissão do conhecimento (FREIRE, 2004) é evitado e nenhuma "colonização" direta das mentes dos estudantes é empreendida pelo professor por meio do emprego da "autoridade epistêmica" dele ou dela (DASCAL, 2009). Na verdade, graças ao princípio 2, a controvertibilidade é trazida à atenção dos estudantes e são dissipadas as ilusões de uma verdade consensual facilmente adquirida e invariavelmente benéfica e de acumulação linear de conhecimento. Mas, não estão essas façanhas em conflito com a necessidade, destacada pelo princípio 3, de formar uma opinião bem fundada, de tomar partidos, de ser ativamente envolvido nos assuntos relevantes, em vez de ser apenas um observador passivo, neutro, que arremeda a pretensa neutralidade de professores mudos? 
((5)) É apenas natural demais que os princípios de uma arte como a da Bildung sejam avaliados, como vimos acima ((4)), em termos de suas consequências práticas. Se se requer que o seu professor exiba diante de você uma persona neutra, quando falar de questões sociais e científicas fundamentais, de onde é que você deverá obter o modelo para uma atitude engajada? O ideal da neutralidade, contudo, não é apenas um efeito posterior da praxis. Ele tem também um antecedente teórico de reputação. No prefácio da segunda edição da Crítica da razão pura, Kant descreve as controvérsias metafísicas entre posições dogmáticas como desacordos bárbaros que a razão não pode resolver. Que a filosofia, ao contrário da física e da matemática, não tenha encontrado um método para resolver suas controvérsias é para Kant um escândalo. Todavia, em vez de propor e desenvolver um tal método, o que Kant faz é antes avisar os filósofos de que eles não deveriam tentar resolver aquelas batalhas metafísicas, tomando partido nelas. Eles deviam de fato perceber que os problemas são insolúveis, embora não inúteis, pois eles podem ser vistos como sintomas das limitações da razão pura; como tais, eles de fato contribuem para com a metafísica crítica de Kant, sem de fato participar em suas controvérsias primordiais. É essa atitude neutra do observador de sintomas e do legislador que com base em tal evidência restringe o escopo da razão pura em questões metafísicas, que ele recomenda por fim na primeira Crítica uma atitude de distanciar-se das controvérsias e não, de engajar-se³ .

((6)) Leibniz também, em um de seus escritos sobre as controvérsias ("On controveries", em Leibniz, 2006, cap. 19), avalia a neutralidade como essencial para a solução apropriada delas. Aqueles que têm que decidir entre as posições de uma confrontação devem confiar no sumário da controvérsia que eles recebem do "rapporteur" [relator], por conter os argumentos essenciais de ambos os lados, formulados corretamente, de maneira organizada e sucinta. Acima de tudo, diz Leibniz, os que tomam decisões devem ser incapazes de detectar no relatório qualquer alusão às preferências do relator por uma das posições. Note-se que, ao contrário de

3 Para uma análise da atitude de Kant e para referências específicas, cf. DASCAL, (2000). 
Kant, Leibniz não recomenda que se abstenha de atacar as controvérsias. Muito pelo contrário, a figura do relator neutro é apenas uma peça no procedimento para resolvê-las com legitimidade.

((7)) Considere-se agora a citação de Humboldt, mencionada duas vezes no artigo de Sander $((10,20))$ como a expressão da concepção de Bildung que ele está tentando reavivar: "die Verknüpfung unseres Ich mit der Welt". Em vez de realçar na conexão entre mundo e eu a direção "mundo $>$ eu", ao mencionar a multiperspectividade que resulta do fato de que na mente de cada eu o mundo é refletido diferentemente, eu realçaria igualmente, na companhia de Humboldt, a orientação "eu > mundo". Pois cada eu não apenas percebe o mundo com sua "individualidade total", mas também compromete o mundo, isto é, age de uma maneira diferente, como indivíduo específico que ele ou ela é. Isso é particularmente importante, quando se trata de controvérsias, em que a tomada de partidos não é uma mera tarefa contemplativa, mas é agir com a individualidade inteira de alguém. Parece-me que essa exigência de Humboldt sugere que ele deve ver como bastante implausível que alguém possa ter êxito ao dividir o "professor" individual completo em um componente não comprometido o que meramente apresentaria a controvertibilidade na sala de aula - e um componente comprometido - que tem que ser preparado como ator a fim de ser capaz de parecer neutro vis-à-vis uma controvérsia que signifique algo para ela ou ele.

((8)) Eu tenho falado de "tomar partido" como se essa fosse a única maneira possível de engajar-se em uma controvérsia. Isso seria o caso, de fato, se controvérsias fossem ou "discussões" (o debate científico ideal sobre um problema que pode ser resolvido por prova experimental ou matemática) ou "disputas" (a confrontação sem solução entre adversários que nem sequer admitem a possibilidade de que o oponente possa estar certo). Eu sugeri dar também um sentido técnico para o termo "controvérsia" para denotar a alternativa a meio caminho entre esses dois polos: um debate em que cada lado pode estar parcialmente certo e parcialmente errado (DASCAL ,1998, 2000). O próprio Leibniz, famoso por sua tentativa de criar uma Characteristica Universalis por meio da qual seria possível 
resolver controvérsias calculando qual das posições opostas é verdadeira, reconheceu que para muitos problemas e controvérsias em nossa vida um tal método não pode ser empregado. Ele advogava nesses casos um comprometimento que não significava esposar um dos polos de uma oposição dicotômica, mas antes questionar o caráter dicotômico e buscar uma maneira de conciliar as posições, uma vez que não sejam mais percebidos como contraditórios strictu senso. ${ }^{4} \mathrm{O}$ desenvolvimento de tais alternativas intermediárias por meio da cuidadosa elaboração de conceitos híbridos, teorias ou políticas híbridas, que são em todo caso necessários em muitas questões contingentes, é também um dos mais eficientes meios de participação fecunda em controvérsias reais e com isso contribuem para o avanço do conhecimento.

((9)) Para concluir, umas poucas observações sobre o que me parece ser a principal alegação epistemológica de Sander: sua contenda quanto à inclusão da controvertibilidade e multiperspectividade nas concepções de ciência e de conhecimento pressupõe a adoção de uma posição construtivista. A reação imediata seria provavelmente observar que há muitos empregos para o termo "construtivismo", e o acordo ou a discordância com a alegação de Sander dependeria de saber o que ele quer exatamente dizer com isso. Devo admitir que ele se esforça para esclarecer seu significado. Contudo, talvez devido ao fato de virmos de diferentes perspectivas disciplinares, seus esclarecimentos não são bem sucedidos para me informar se ele se apóia na costumeira oposição "construtivismo" vs. "realismo" (em particular a variedade de realismo chamada "ingênua"). Há passagens no artigo de Sander em que a objetividade da ciência (natural) é defendida impetuosamente, tanto quanto faria um realista ingênuo ((15)), o que contrasta com passagens em que o "moderno construtivismo" é descrito como incompatível com a hipótese assumida de que há um mundo lá fora que é "verdadeiramente" representado pelo conhecimento científico $((12,13))$. Eu vou ficar naturalmente grato a Wolfgang Sander por explicar como se empenha na controvérsia (na verdade, controvérsias) que a

${ }_{4}^{4}$ Para uma análise dos dois tipos de abordagens conciliatórias de assunto científico controvertido, cf. Dascal e Firt (no prelo). 
dicotomia (na verdade, dicotomias) construtivismo vs. realismo engendra. Para o leitor que acompanhou minhas observações até este ponto, não seria difícil adivinhar qual seria meu jeito de engajar em uma controvérsia. Seria desdicotomizando a oposição ${ }^{5}$, e assim transformando a oposição em uma "controvérsia" (em meu sentido técnico), capaz de produzir uma conciliação entre epistemologias aparentemente irreconciliáveis (ver DASCAL, 2006a). Entre outros resultados dessa atitude, o inquestionável fato de que a ciência, sendo uma atividade humana, é sempre contextual um fato que nem os realistas ingênuos negam - não implica, pace o título de Knorr-Cetina (1981), a redução construtivista realizada em alguns quadrantes (Ver DASCAL, 1997). Considerando-se os diversos aspectos que me atraíram no artigo que eu comentei apenas parcialmente aqui e com o qual não tenho nenhum receio em concordar, eu desconfio que seu autor não se recusaria a me acompanhar nesse esforço de conciliação.

\section{Referências}

DASCAL, Marcelo. 1997. Critique without critics? Science in Context 10(1): 39-62.

. 1998. The study of controversies and the theory and history of science. Science in Context 11 (2) 147-154, . 2000. Epistemology and controversies. In: TIAN YU CAO (Org.). Philosophy of Science [= Volume 10 of Proceedings of the Twentieth World Congress of Philosophy]. Philadelphia: Philosophers Index Inc., 159-192; 2000.

. 2005. The balance of reason. In: D. Vanderveken (Ed.). Logic, Thought and Action. Dordrecht: Springer, 22-47.

. 2006a. Die Dialektik in der kollektiven Konstruktion wissenschaftlichen Wissens. In W-A. Liebert M-D. Weitze (Org.). Kontroversen als Schlüssel zur Wissenschaft? Wissennskulturen in sprachlicher Interaktion. Bielefeld: Transcript Verlag. 19-38.

5 Para as noções de "desdicotomização" "dicotomização", cf. Dascal (2008). 
. 2006b. Normative rationality against práxis in scientific debates? EWE 17(2): 58-60.

2008. Dichotomies and types of debate. In: F. H. van Eemeren e B. Garssen (Org.). Controversy and Confrontation: Relating Controversy Analysis with Argumentation Theory. Amsterdam: John Benjamins, 27-50.

. 2009. Colonizing and decolonizing minds. In I Kuçuradi (Org.). World Philosophy Day 2007. Ankara: Philosophical Society Of Turkey, 308-331.

DASCAL, M.; FIRT, E. Leibniz's conciliatory approaches in scientific controversies. In M. (Org.). The Practice of Reason: Leibniz and his Controversies. Amsterdam: John Benjamins [no prelo].

FREIRE, P. 2004. Pedagogy of the Oppressed, edição do $30^{\circ}$ aniversário; Trad. M. B. Ramos. Nova York: Continuum Press. 2004.

KNORR-CETINA, K. 1981. The manufacture of Knowledge: an Essay on the Constructivist and Contextual Nature of Science. Oxford: Pergamon.

LEIBNIZ, G. W. 2006. The Art of Controversies. Trad. e org com ensaio introdutório e notas por M. Dascal. Dordrecht: Springer.

SANDER. W. Bildung und Perspektivität: Kontroversität und Indoktrinationsverbot als Grundsätze von Bildung und Wissenschaft, EWE 20 (2009) 239-248.

Data de registro: 04/04/2010 Data de aceite: 28/02/2011 